\title{
Analysis of Effective Optimization of Construction Technology in Municipal Engineering Construction Projects
}

\author{
Dai Shasha ${ }^{1} *$ \\ ${ }^{1}$ Rizhao Polytechnic, 276826, Rizhao, Shandong, China
}

\begin{abstract}
Municipal engineering construction is related to people's living standards and environment. To improve the quality of municipal engineering construction projects, it is necessary to strengthen the management and effectively optimize construction technology, and improve the construction efficiency and quality. Based on this, this article will analyze the significance of optimizing construction technology in municipal engineering construction projects, and propose construction technology optimization strategies to improve the level of municipal engineering construction in China.
\end{abstract}

\section{Introduction}

Municipal engineering is closely related to people's daily life. Municipal engineering construction projects usually include many construction technologies, such as water supply and drainage technology, urban road engineering construction technology, urban greening technology. Optimizing the construction technology of municipal engineering construction projects can effectively improve construction quality and efficiency, and reduce construction costs. Construction technology runs through the entire construction, including preparation, construction, and completion acceptance. It is necessary to make a design plan for the entire construction and plan it reasonably, which is of great significance for improving the quality of the entire construction.

\section{Significance}

\subsection{Saving construction cost and simplifying}

In recent years, with the continuous improvement of urbanization, there have been more and more municipal engineering construction projects. The construction difficulty has also increased and the construction links have become more complicated. In the actual construction of a project, it will be restricted and affected by the natural environment and topographical conditions, which will affect the efficiency of construction. Optimizing the construction technology of municipal engineering can effectively simplify the construction, reasonably control the construction time, and save construction costs to a certain extent. It can make full use of construction materials, maximize the input of construction materials and reduce the waste of construction materials to better control costs [1].

\subsection{Improve construction quality and sustainable development}

Optimizing construction technology is of great significance to improving construction quality and efficiency. With the development and progress of science and technology, new construction techniques and materials have emerged, but many constructions have not mastered skilled construction techniques, which also has a certain impact. Optimizing construction technology not only has a positive effect on improving the quality of construction, but also has a very important significance for improving the overall level of construction departments and promoting the sustainable development of industry.

\subsection{Promote the national economy}

The construction technology of municipal engineering projects directly affects the quality of use of the project, not only related to the development of urbanization but also related to the quality of life of urban residents. Optimizing municipal engineering construction technology can effectively improve the quality of municipal construction, reduce environmental pollution caused by construction, improve the environmental and social benefits of construction projects, and improve the quality of life of urban residents and the level of the city.

\section{Construction technology optimization strategies}

\subsection{Establish construction technology management objectives}

Before the construction of municipal engineering construction, the corresponding preparations must be 
finished. The most important thing is to effectively optimize the corresponding goals, so that the specific construction can be more efficient and the project can be developed rapidly. The construction management personnel need to conduct a more specific and effective analysis of the problems existing in the project construction, and take targeted measures in accordance with the basic situation of the project (figure 1).

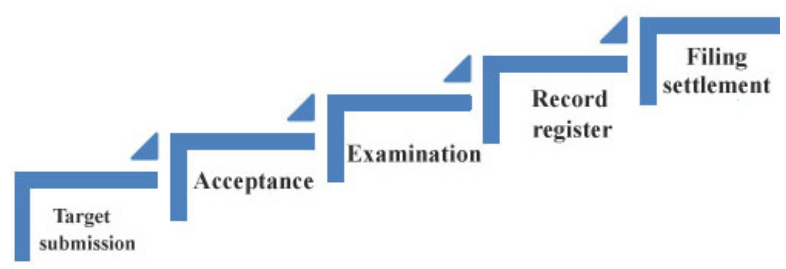

Fig. 1. The basic situation of the project

Construction management personnel should do the following in the process of rationally optimizing construction goals. Firstly, the establishment of the plan conforms to the relevant latest standards established by the state. For example, during the construction of municipal road engineering sub-grade, the allowable deviation of sub-grade stonework varies greatly from project to project. That is, the allowable deviation of the elevation item is $+50 \mathrm{~mm} \sim-200 \mathrm{~mm}$, and for the cutting depth, when the cutting depth is less than 3 , the allowable deviation is $+100 \mathrm{~mm} \sim 0 \mathrm{~mm}$. When the cutting depth is greater than 3, the allowable deviation is $+200 \mathrm{~mm} \sim$ $50 \mathrm{~mm}$. Secondly, it is necessary to make reasonable analysis and judgments on the difficulty of construction, and make more detailed formulations from a multidimensional perspective. Thirdly, it should be noted that when determining and optimizing goals, planning must be based on long-term goals. Fourthly, the establishment of goals should also be based on actual construction experience, and fully apply the method of close integration of theory and practice. One should not overestimate one's own ability, and proceed from one's own level to build rationally[2]. For example, a company undertook the reconstruction of urban arterial roads. The structure of which is a lime soil sub-base, cement stabilized crushed stone base and asphalt concrete surface. According to the company's actual situation and the main road conditions, the company decided to complete the demolition in May. The construction goal was completed in November, and a mixing station was set up outside the city. It can carry out construction material transportation according to night transportation and daytime construction plan. It ensures the smooth implementation and the realization of the goals [3]. (Examples of related municipal projects)

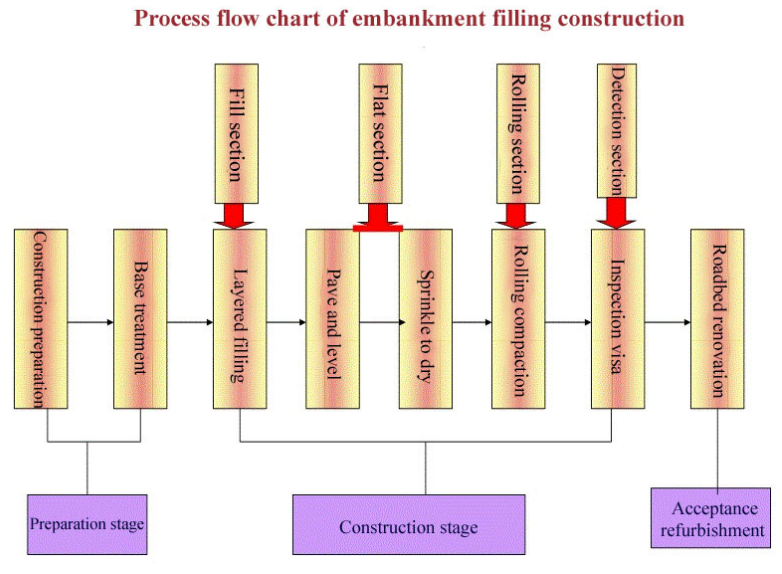

Fig. 2. Flowchart of construction process for embankment

\subsection{Specific new technology approaches}

The quality of buildings is closely related to the construction, and for the construction projects of municipal engineering, it is necessary to effectively guarantee its quality. Therefore, it should improve the construction quality. The fundamental way is to improve the targeted construction technology. Therefore, it can be found that the strict requirements for construction quality can be reversed to promote the construction technology. In the application of technical methods, reverse construction, pumping coagulation technology, and overall sliding form and overall climbing form method (for example, method diagrams) can be used to continuously improve the quality of buildings [4]. In the implementation of steel structure technology, it should be noted that the temperature can withstand $250^{\circ} \mathrm{C}$ and below, so as to ensure that the steel structure remains stable. Figure 3 is a schematic diagram of the main points of the reverse construction method.

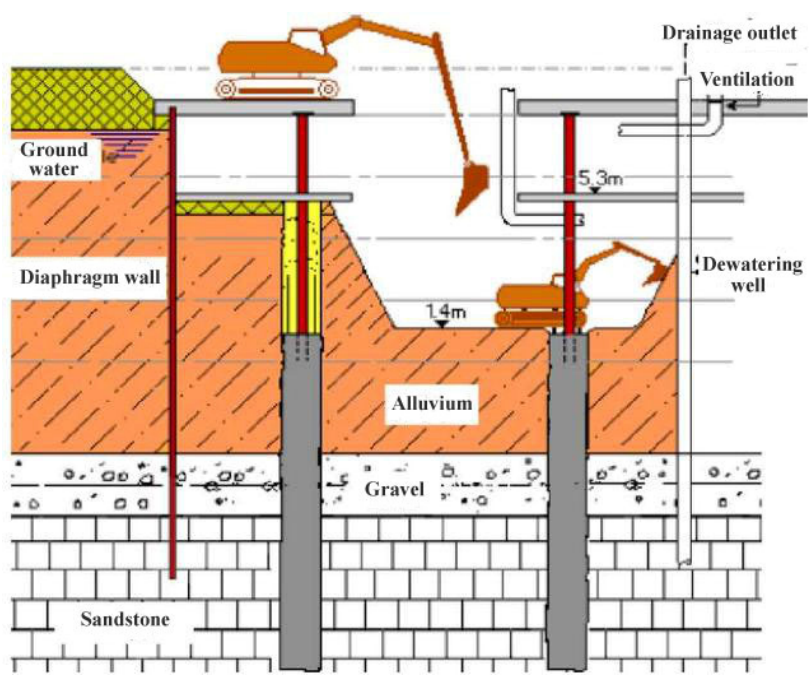

Fig.3. A schematic diagram of the main points of the reverse construction method.

\subsection{Establish engineering quality management}

Project establishment is the basic link of project 
construction. Starting from this until the end of the project, a higher level of monitoring of the project is required, so that the project construction can be well guaranteed to meet the specifications. First of all, it should effectively control all aspects of the project based on this. Each construction link should be clearly carried out in accordance with the design plan and management system and set up a responsibility system to implement each job to a specific post. At the same time, a special inspection team needs to be established when carrying out the construction of the relevant. The quality of the project should be inspected and evaluated reasonably to ensure that each link passes the evaluation before entering the next procedure. It is also necessary to establish a reward and punishment mechanism to reward the team that strictly abide by the construction code and good construction quality, and punish the lazy and poor construction effect team to optimize the construction technology.

\subsection{Enhance monitoring of equipment and materials}

There is a big gap between the current and the traditional construction, which means that the replacement of the equipment plays an important role in improving the overall level of the project. Therefore, if it needs to improve the efficiency of the project, it will be better to optimize the construction project under the premise of meeting the relevant standards.

For example, technical management personnel should effectively establish equipment and material supervision departments in accordance with the current situation. Its functions are shown in figure 4. Its main function is to perform repeated accounting of the materials needed. For the required equipment, a more detailed inspection must be carried out. First of all, for the mechanical equipment to be used, it should be scientifically tested with the corresponding inspection standards to fully ensure that the equipment can be kept in the best condition before using. In this way, the impact on the construction is minimized and the efficiency of the original equipment is maximized, so as to effectively improve the overall progress.

Secondly, it is also very important for the daily maintenance of equipment. Equipment not needed in the current process of the project should be kept and sealed up as the requirements. And it needs to carry out daily maintenance to ensure its working state to the greatest extent, so that it can be more efficiently and quickly put into construction when it is used next time. At the same time, the rational use of construction materials is also an important way to innovate and optimize construction technology. It is necessary to pay attention to the analysis from the introduction of construction materials. The imported materials must be purchased from formal channels, and the relevant procedures for the materials must be complete. At the same time, the construction department must also have its own material control system, and the newly purchased materials must pass reasonable testing before they can be used. The unqualified materials should be returned or destroyed to prevent them from entering the market again and hindering the construction progress of other projects [5].

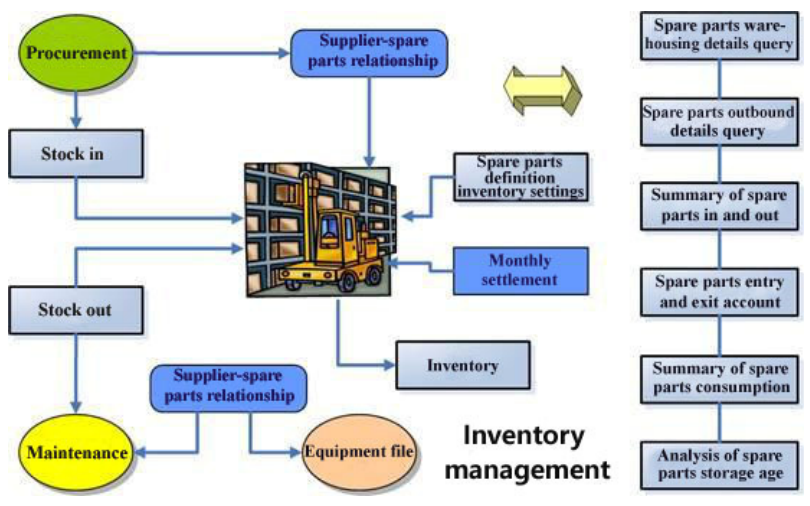

Fig.4. Flow chart of equipment and materials supervision for construction projects

\subsection{Upgrade the professional level of construction personnel}

The importance of the most direct construction personnel in project implementation is self-evident, and they play a key role in construction technology and application. The construction personnel can determine the level of the entire project in a certain sense. Strengthening the professional quality and knowledge of the construction personnel will directly promote the optimization of the project construction.

For example, construction management personnel can effectively improve their professionalism and technical level through regular training of construction personnel. First of all, the basic awareness of construction personnel can be improved through training lectures. The the lecture can best be about the current advanced construction methods and cases in the construction industry at home and abroad. This allows the construction staff to have a certain concept of the advanced field methods. Decomposing the specific technology in the following can easily grasp the technical points effectively. Secondly, after the theoretical lectures are finished, there should be customized training for construction personnel of different positions, technical levels, etc. in stages. After the re-training is over, a reasonable evaluation test should be conducted on all construction personnel, so that the management personnel can have a true and objective understanding of the progress of each construction personnel in the current stage, and use this to formulate training goals for the next stage. Finally, for the assessment, reasonable scheduling and rotation should be carried out to establish the personalized matching of the assessment standards at different stages, enhance the flexibility of training tasks, make it better to achieve the expected results, and promote the leapfrog optimization [6].

\section{Conclusion}

To sum up, municipal engineering construction technology directly affects the quality of the project. 
Optimizing construction includes customizing strict construction quality standards, innovating construction technology, strengthening the management of construction equipment, construction materials and personnel, implementing construction supervision and control, ensuring timely detection of problems, and taking timely and effective measures. It can improve the overall level. In addition, it is also necessary to increase the importance of enterprises on the optimization and management of construction technology. In many construction companies, there are no goals for the management of municipal engineering construction technology, lack of technical planning and design, which will reduce the initiative of construction technical managers. It is necessary for companies to continuously increase their attention to construction technology optimization, improve their market competitiveness, and continuously optimize construction technology management.

\section{References}

1. Chen Junxiang. Analysis of effective optimization of construction technology in municipal engineering construction projects[J]. Commodities and Quality, 2019, (43):163.

2. Guo Zhiyong. Analysis of effective and optimized construction technology in municipal engineering construction projects[J]. Charming China, 2020, (13):344-345.

3. Liu Jiaqi. The management of municipal engineering construction project[J]. Construction Technology Development, 2019(S1): 16.

4. Sun Degui. The legal compliance procedures and formalities of highway and municipal engineering construction projects[J]. Commodity and Quality, 2019, 42(034):206.

5. Tang Zheping. Analysis of effective and optimized construction technology in municipal engineering construction projects[J]. Engineering Technology Research, 2018, (1):89-90.

6. Wu Jingwen. Effective optimization of construction technology in municipal engineering construction projects[J]. Electronic Paradise, 2019(5):0079-0079. 